\title{
Every new technique either conservative or surgical is good?
}

\author{
Konservatif veya cerrahi her yeni yöntem iyi midir? \\ O. Şahap Atik, MD \\ Professor of Orthopedic Surgery, Turkish Joint Diseases Foundation, Ankara, Turkey
}

Patellar tendon seems to benefit from platelet-rich plasma (PRP) injections, while there is no proven benefit for Achilles tendon, rotator cuff pathology, or lateral elbow tendinopathy. ${ }^{[1]}$

In another study, compared to PRP, human recombinant epidermal growth factor caused more increase in healing tissue at neovascularization, tenocyte, fibroblast, collagen, and tissue macrophage levels; thus it may be a viable option for tendon healing. ${ }^{[2]}$

Platelet-rich plasma could be a promising bioactive scaffold for the delivery of chondroprogenitors in cartilage healing due to its synergistic effect in supporting cell proliferation, maintaining cell viability and favoring extracellular matrix production..$^{[3]}$

The combination of intraarticular infiltrations with intraosseous infiltrations of PRP regulates the biological processes of the tissues, reducing the inflammatory environment and modulating the overexpression of biomolecules that generate an aberrant cellular behavior. Preliminary clinical results are promising, while further research and developing adequate protocols are necessary. ${ }^{[4]}$

Due to the limitations of conventional treatments for focal chondral defects of the knee, orthobiologics have recently become an area of interest. Orthobiologics used for cartilage defects include bone marrow aspirate concentrate, adipose-derived mesenchymal stem cells, PRP, and micronized allogeneic cartilage. ${ }^{[5]}$

There is conflicting evidence regarding the use of orthobiologics for osteoarthritis and focal chondral defects. ${ }^{[6]}$ Although positive results are being reported in the pre-clinical setup, more clinical data are required in order to make a conclusion on this new concept. ${ }^{[7]}$

The addition of PRP to a poly lactic-co-glycolic acid (PLGA) scaffold with continuous passive motion in osteochondral defects may be beneficial for hyaline cartilage and subchondral bone tissue repair. However, PRP alone (with or without PLGA implants) is limited to osteochondral defect repair without significant regeneration. ${ }^{[8]}$

Preliminary results in survivorship of patients with early stages of osteonecrosis of the femoral head treated with core decompression in association with mesenchymal stem cells implantation, PRP injection, and synthetic bone graft were good. ${ }^{[9]}$

Platelet-rich plasma injection may have a positive role in the treatment of early stages of steroidassociated osteonecrosis of femoral head in a rabbit model. ${ }^{[10]}$

In a study, the possible effects of leukocyte concentration in the content of PRP and the administration of PRP using a drug delivery system on chondrocyte proliferation are searched in vitro conditions. Authors showed that leukocyte-rich PRP administered with a delivery system such as hydrogel is more efficient than conventional applications of PRP in the treatment of cartilage damage in vitro. ${ }^{[1]}$

In another study, the results indicate that leukocytepoor PRP may promote tendon healing through anabolic effects while leukocyte-rich PRP may impair the repair process. ${ }^{[12]}$

Finally, current clinical experience on orthobiologics should be regarded as first steps for 
the new concept of musculoskeletal system healing and is still in experimental stage. ${ }^{[7]}$

No definitive conclusions can be established about the effects of PRP in such conditions since most studies are of low to moderate methodological quality and use variable PRP protocols. For these reasons, there is a growing debate regarding PRP's clinical efficacy. ${ }^{[13]}$

Orthopedic surgeons should be aware of the ongoing uncertainty about the evidence behind PRP therapies and inform patients about this fact.

\section{REFERENCES}

1. Filardo G, Di Matteo B, Kon E, Merli G, Marcacci M. Platelet-rich plasma in tendon-related disorders: results and indications. Knee Surg Sports Traumatol Arthrosc 2018;26:1984-99.

2. Sarıkaya B, Yumuşak N, Yigin A, Sipahioğlu S, Yavuz Ü, Altay MA. Comparison of the effects of human recombinant epidermal growth factor and platelet-rich plasma on healing of rabbit patellar tendon. Eklem Hastalik Cerrahisi 2017;28:92-9.

3. Vinod E, Vinod Francis D, Manickam Amirtham S, Sathishkumar S, Boopalan PRJVC. Allogeneic platelet rich plasma serves as a scaffold for articular cartilage derived chondroprogenitors. Tissue Cell 2019;56:107-13.

4. Delgado D, Garate A, Vincent H, Bilbao AM, Patel R, Fiz N, et al. Current concepts in intraosseous Platelet-Rich Plasma injections for knee osteoarthritis. J Clin Orthop Trauma 2019;10:36-41.

5. Southworth TM, Naveen NB, Nwachukwu BU, Cole BJ, Frank RM. Orthobiologics for Focal Articular Cartilage
Defects. Clin Sports Med 2019;38:109-22.

6. Sherman BJ, Chahla J, Glowney J, Frank RM. The Role of Orthobiologics in the Management of Osteoarthritis and Focal Cartilage Defects. Orthopedics 2019;42:66-73.

7.. Sezgin EA, Atik OŞ. Are orthobiologics the next chapter in clinical orthopedics? A literature review. Eklem Hastalik Cerrahisi 2018;29:110-6.

8. Chang NJ, Erdenekhuyag Y, Chou PH, Chu CJ, Lin CC, Shie MY. Therapeutic Effects of the Addition of PlateletRich Plasma to Bioimplants and Early Rehabilitation Exercise on Articular Cartilage Repair. Am J Sports Med 2018;46:2232-41.

9. D’Ambrosi R, Biancardi E, Massari G, Ragone V, Facchini RM. Survival Analysis after Core Decompression in Association with Platelet-Rich Plasma, Mesenchymal Stem Cells, and Synthetic Bone Graft in Patients with Osteonecrosis of the Femoral Head. Joints 2018;6:16-22.

10. Karakaplan M, Gülabi D, Topgül H, Elmalı N. Does plateletrich plasma have a favorable effect in the early stages of steroid-associated femoral head osteonecrosis in a rabbit model? Eklem Hastalik Cerrahisi 2017;28:107-13.

11. Yaşar Şirin D, Yılmaz İ, İsyar M, Öznam K, Mahiroğulları M. Does leukocyte-poor or leukocyte-rich platelet-rich plasma applied with biopolymers have superiority to conventional platelet-rich plasma applications on chondrocyte proliferation? Eklem Hastalik Cerrahisi 2017;28:142-51.

12. Yan R, Gu Y, Ran J, Hu Y, Zheng Z, Zeng M, et al. Intratendon Delivery of Leukocyte-Poor Platelet-Rich Plasma Improves Healing Compared With Leukocyte-Rich Platelet-Rich Plasma in a Rabbit Achilles Tendinopathy Model. Am J Sports Med 2017;45:1909-20.

13. Atik OŞ. Platelet-rich plasma: Everything new may not be good enough! Eklem Hastalik Cerrahisi 2017;28:63. 